\title{
A Hospital based Cross Sectional Study Evaluating Haemoglobin, Iron Profile and Thyroid Function Tests in Women with Telogen Effluvium, Female Pattern Hair Loss, and Alopecia Areata
}

\author{
Amatya $\mathbf{B}^{1}$, Joshi $\mathbf{S}^{1}$ \\ ${ }^{1}$ Department of Dermatology and Venereology, Nepal Medical College and Teaching Hospital, Attarkhel, Kathmandu, \\ Nepal
}

\begin{abstract}
Introduction: Hair loss is one of the most frequent complaints for which patients see a dermatologist. The three most common causes of hair loss in women are telogen effluvium, alopecia areata and female pattern hair loss.

Objectives: The aim of this study was to investigate haemoglobin, iron profile and thyroid function tests in women with telogen effluvium, alopecia areata and female pattern hair loss.

Materials and Methods: This was a hospital based cross sectional study conducted at the Department of Dermatology and Venereology, Nepal Medical College and Teaching Hospital (NMCTH). We recruited female patients with telogen effluvium, alopecia areata or female pattern hair loss who presented to our outpatient department between June 2019 and July 2020. Clinical and demographic data were collected and haemoglobin, serum iron profile and thyroid function investigated.

Results: A total of 80 patients were recruited in the study period. The most common diagnosis was telogen effluvium $(49,61.25 \%)$ followed by alopecia areata $(18,22.5 \%)$ and female pattern hair loss $(13,16.25 \%)$. Although mean haemoglobin levels were within normal limits, inadequate ferritin levels for normal hair cycle were found in $77.55 \%$ of patients with telogen effluvium, $88.89 \%$ with alopecia areata and $84.61 \%$ with female pattern hair loss. Thyroid abnormalities were less commonly observed with more than $75 \%$ of the patients being euthyroid.

Conclusion: Haemoglobin levels are not representative of true iron status in females with acquired alopecia. We therefore recommend investigating iron profile in all females with telogen effluvium, alopecia areata or female pattern hair loss.
\end{abstract}

Key words: Alopecia areata; Diffuse alopecia; Iron; Thyroid Diseases

\section{Introduction}

$\mathrm{H}$ air loss is one of the most frequent complaints for which patients see a dermatologist. It can be associated with psychological features including low self esteem and depression. ${ }^{1}$ The three most common causes of hair loss in women are androgenetic alopecia, alopecia areata and telogen effluvium. ${ }^{2}$

Funding: No

Conflict of Interest: No

\section{Address of Correspondence}

Dr. Bibush Amatya

Department of Dermatology and Venereology, Nepal Medical College and Teaching Hospital

Attarkhel, Jorpati, Kathmandu, Nepal

Telephone number: 9843854654

E-mail: bibush.amatya@nmcth.edu
Androgenetic alopecia is a common form of hair loss. ${ }^{2}$ When females are affected, there is diffuse hair loss on mid-scalp, which is known as female pattern hair loss. ${ }^{2}$ It primarily occurs due to increased levels and activity

Submitted: $27^{\text {th }}$ January 2021

Accepted: $10^{\text {th }}$ February 2021

Published: $20^{\text {th }}$ February 2021

How to cite this article

Amatya B, Joshi S. A Hospital based Cross Sectional Study Evaluating Haemoglobin, Iron Profile and Thyroid Function Tests in Women with Telogen Effluvium, Female Pattern Hair Loss, and Alopecia Areata. Nepal Journal of Dermatology, Venereology \& Leprology 2021;19(1):9-13. https://doi. org/10.3126/njdvl.v19i1.34551.

\section{(c) (i)}

Licensed under CC BY 4.0 International License which permits use, distribution and reproduction in any medium, provided the original work is properly cited. 
of androgens in genetically susceptible individuals. At the same time, it can also be triggered or worsened by conditions that induce telogen effluvium including nutrient deficiencies and thyroid disorders. ${ }^{3}$

Alopecia areata (AA) is a common autoimmune non-scarring hair loss disorder that is clinically heterogeneous. ${ }^{4}$ The disorder may be limited to few areas on the scalp or body, may affect the entire scalp (alopecia totalis) or the whole body (alopecia universalis). ${ }^{4}$ As the disorder is considered to be autoimmune, it can be associated with other autoimmune diseases including thyroid disorders. ${ }^{4}$

Telogen effluvium is a non-scarring hair loss disorder characterized by increased shedding of telogen hairs. ${ }^{5}$ It may be acute lasting less than 6 months or chronic when duration is longer than 6 months. ${ }^{6}$ While acute telogen may be triggered by fever, surgical trauma or starvation, chronic telogen effluvium is usually associated with autoimmune thyroid disorders, iron deficiency and other nutritional deficiencies. ${ }^{7}$

Telogen effluvium is present in roughly $50 \%$ of hyperthyroid and $33 \%$ of hypothyroid patients. ${ }^{8}$ Hair loss may be the first manifestation of these thyroid disorders and can lead to early detection of these conditions. At the same time, treatment of thyroid disorders usually leads to resolution of hair loss if initiated early. ${ }^{8}$

Iron deficiency can also cause hair loss. ${ }^{9}$ This becomes more evident when serum ferritin level is below $20 \mathrm{ng} /$ $\mathrm{mL}$. It is hypothesized that iron deficiency decreases proliferation of hair matrix cells resulting in hair follicles failing to re-enter anagen after completing the telogen phase. ${ }^{9}$

The primary objective of this study was therefore to detect derangements in haemoglobin, iron profile and thyroid function in patients presenting with telogen effluvium, female pattern hair loss and alopecia areata. Early detection of these derangements with timely intervention can halt the progression of hair loss and at the same time stimulate new hair growth.

\section{Materials and Methods}

This was a hospital based cross sectional study conducted at tertiary level hospital/medical college. We recruited all female patients with telogen effluvium, scalp alopecia areata or female pattern hair loss, who visited the dermatology outpatient department between June, 2019 and July, 2020. All participants provide written informed consent for participation. The Institutional Review Committee (IRC) granted approval to conduct the study (reference number 043-075/076).

We diagnosed telogen effluvium based on the clinical picture of diffuse hair loss and positive hair pull test. Alopecia areata was diagnosed based on presence of round or oval bald smooth patch on the scalp. We diagnosed female pattern hair loss based on hair loss in biparietal, bitemporal or vertex regions with preservation of anterior hair implantation line. In cases of diagnostic difficulty, we employed trichoscopy to differentiate female pattern hair loss (presence of vellus transformation, perifollicular pigmentation and yellow dots) from telogen effluvium. ${ }^{10}$

At enrolment, the investigators filled a clinical proforma to obtain information on patient number, name, age, sex and diagnosis. We tested each patient for haemoglobin, serum iron, serum ferritin, transferrin saturation, total iron binding capacity, free T3, free T4 and TSH levels. We uploaded the data into a secure password protected database using Microsoft Excel. Strict confidentiality was maintained throughout the study.

Data analysis was performed with the Statistical Package for Social Sciences (SPSS) version 16. Descriptive statistics were utilized to compute the mean and standard deviation of age, haemoglobin, ferritin, free T3, free T4 and TSH. We used KolmogorovSmirnov Z and Shapiro-Wilk tests to check for normality of haemoglobin, serum iron, serum ferritin, free T3, free T4 and TSH. We employed one way analysis of variance (ANOVA) to compare mean haemoglobin and serum iron in the three conditions while KruskalWallis $\mathrm{H}$ test was used to compare mean ferritin levels. Fischer's exact test was utilized to compare iron and thyroid status in the three conditions. Results were considered statistically significant at an alpha of $5 \%$ ( $p$ $\leq 0.05)$.

\section{Results}

A total of 80 patients were enrolled in the study. The most common diagnosis was telogen effluvium (49 patients, 61.25\%) followed by alopecia areata (18 patients, $22.5 \%$ ) and female pattern hair loss (13 patients, $16.25 \%)$.

The mean age of the participants was $30.22 \pm 11.35$ years with a range of 56 years ( $9-65$ years). The highest percentage of participants $(68.7 \%)$ belonged to the age group 16-35 years. 
Haemoglobin levels ranged from 9.2 to $16.1 \mathrm{~g} / \mathrm{dL}$ (mean: $12.59 \pm 1.16$ ). Serum iron levels ranged from 16 to $150 \mu \mathrm{g} / \mathrm{dL}$ (mean: $79.75 \pm 2.78$ ) while serum ferritin levels ranged between 4.59 and $453.41 \mathrm{ng} / \mathrm{mL}$ (mean: $48.29 \pm 6.42)$. Anaemia $(\mathrm{Hb}<12 \mathrm{~g} / \mathrm{dL}$ ) was present in 22 patients $(27.5 \%)$, iron deficiency (ferritin levels $<12$ $\mathrm{ng} / \mathrm{mL}$ ) in 13 patients (16.25\%), iron depletion (serum ferritin: $>12-<20 \mathrm{ng} / \mathrm{mL}$ ) in 17 patients $(21.25 \%)$ and serum ferritin level lower than required for normal hair cycle (serum ferritin: $>20-<70 \mathrm{ng} / \mathrm{mL}$ ) in 35 patients (43.75\%). Overall, $81.25 \%$ of the participants had ferritin levels that were inadequate for normal hair cycle.

The mean haemoglobin, iron, and ferritin values in all three groups of participants are listed in table 1. The mean haemoglobin, iron and ferritin values were within the normal limits in all three groups and the differences were not statistically significant. Anaemia $(\mathrm{Hb}<12 \mathrm{~g} / \mathrm{dL}$ ) was observed in 14 (28.6\%) of participants with telogen effluvium, 2 (11.1\%) with alopecia areata and 6 (46.2\%) with female pattern hair loss.

Table 2 gives a detailed breakdown of iron deficiency (serum ferritin < $12 \mathrm{ng} / \mathrm{mL}$ ), iron depletion (serum ferritin: $>12-<20 \mathrm{ng} / \mathrm{mL}$ ), ferritin levels lower than required for normal hair cycle (serum ferritin: >20$<70 \mathrm{ng} / \mathrm{mL}$ ) and adequate ferritin levels for normal hair cycle (serum ferritin $\geq 70 \mathrm{ng} / \mathrm{mL}$ ) in all three conditions. A total of 65 patients (81.25\%) had ferritin levels that were inadequate for normal hair cycle. A non-statistically significant difference $(p=0.354)$ was found in ferritin levels in the three conditions with 77.55\% telogen effluvium patients, $88.89 \%$ alopecia areata patients and $84.61 \%$ female pattern hair loss having ferritin levels that were inadequate for normal hair cycle.

The levels of TSH ranged from 0.005 to $12.06 \mu \mathrm{lU} /$ $\mathrm{mL}$ (mean: $2.78 \pm 2.15$ ), fT3 from 1.45 to $5.77 \mathrm{pg} / \mathrm{mL}$ (mean: $3.63 \pm 0.79$ ) and fT4 from 0.5 to $2.06 \mathrm{ng} / \mathrm{dL}$ (mean: $0.99 \pm 0.25$ ). The majority of the patients were euthyroid $(63,78.8 \%)$. An equal number of patients (4, 5\%) suffered from subclinical hypothyroidism, primary hypothyroidism, secondary hypothyroidism and subclinical hyperthyroidism. Only one patient $(1.2 \%)$ had secondary hyperthyroidism while there were no patients with primary hyperthyroidism. Table 3 gives a detailed breakdown of thyroid status in all three conditions. In all three conditions, the majority of the patients were euthyroid ( $p=0.027$ ). The interpretation of thyroid function test was based on the recommendations of Koulouri and Gurnell. ${ }^{11}$

Table 1: Mean haemoglobin, iron and ferritin levels for each condition

\begin{tabular}{|c|c|c|c|}
\hline Diagnosis & Mean haemoglobin $(\mathbf{g} / \mathbf{d L})$ & Mean iron $(\boldsymbol{\mu g} / \mathbf{d L})$ & Mean ferritin $(\mathbf{n g} / \mathbf{m L})$ \\
\hline Telogen effluvium & $12.42 \pm 1.09$ & $79.20 \pm 2.53$ & $54.45 \pm 7.18$ \\
\hline Alopecia areata & $13.08 \pm 0.89$ & $87.67 \pm 3.32$ & $43.38 \pm 6.16$ \\
\hline Female pattern hair loss & $12.55 \pm 1.56$ & $70.85 \pm 2.81$ & $31.92 \pm 2.61$ \\
\hline & $p=0.112$ & $p=0.248$ & $p=0.307$ \\
\hline
\end{tabular}

Table 2: Iron deficiency, iron depletion and inadequate ferritin levels for normal hair cycle for each condition

\begin{tabular}{|c|c|c|c|c|}
\hline Diagnosis & Iron deficiency & Iron depletion & $\begin{array}{c}\text { Inadequate ferritin } \\
\text { for normal hair cycle }\end{array}$ & $\begin{array}{c}\text { Adequate ferritin for } \\
\text { normal hair cycle }\end{array}$ \\
\hline TE & $7(14.29 \%)$ & $7(14.29 \%)$ & $24(48.98 \%)$ & $11(22.45 \%)$ \\
\hline AA & $3(16.67 \%)$ & $6(33.33 \%)$ & $7(38.89 \%)$ & $2(11.11 \%)$ \\
\hline FPHL & $3(23.08 \%)$ & $4(30.77 \%)$ & $4(30.77 \%)$ & $2(15.38 \%)$ \\
\hline
\end{tabular}

Index

TE - Telogen effluvium, AA - Alopecia areata, FPHL - Female pattern hair loss

Table 3: Thyroid function status for each condition

\begin{tabular}{|c|c|c|c|c|c|c|c|}
\hline & EUT & SUHO & PHO & SHO & SUHR & PHR & SHR \\
\hline TE & $42(85.71 \%)$ & $1(11.11 \%)$ & $1(11.11 \%)$ & $2(4.08 \%)$ & $3(6.12 \%)$ & 0 & 0 \\
\hline AA & $13(72.22 \%)$ & $3(16.67 \%)$ & $1(5.56 \%)$ & 0 & $1(5.56 \%)$ & 0 & 0 \\
\hline FPHL & $8(61.54 \%)$ & 0 & $2(15.38 \%)$ & $2(15.38 \%)$ & 0 & 0 & $1(7.69 \%)$ \\
\hline
\end{tabular}

\section{Index}

TE - Telogen effluvium, AA - Alopecia areata, FPHL - Female pattern hair loss, EUT - Euthyroid,

SUHO - Subclinical hypothyroidism, PHO - Primary hypothyroidism, SHO - Secondary hypothyroidism,

SUHR - Subclinical hyperthyroidism, PHR - Primary hyperthyroidism, SHR - Secondary hyperthyroidism 


\section{Discussion}

The three most common causes of hair loss in women are telogen effluvium, female pattern hair loss, and alopecia areata. ${ }^{2}$ Anaemia $(\mathrm{Hb}<12 \mathrm{~g} / \mathrm{dL})$ was present in 22 patients $(27.5 \%)$ in our study. This differs from similar studies done elsewhere where the prevalence of anaemia in acquired alopecias has ranged from $0 \%$ in Australia ${ }^{12}$ to $73.4 \%$ in India. ${ }^{13}$ Studies done in Nepal have shown anaemia prevalence in general female population to be around $60 \% .{ }^{14}$

In our study, anaemia was present in 14 (28.6\%) patients with telogen effluvium while iron deficiency was observed in 7 (14.29\%) patients. This contrasts with the study done by Deo et al. in India in 2014-15 where $75 \%$ of patients with telogen effluvium were anaemic while only $9.5 \%$ were iron deficient. As our study population was predominantly urban, the prevalence of anaemia in our study may have been lower compared to studies conducted in rural and peri-urban areas. We followed the categorization of serum ferritin levels given by Zhang et al. ${ }^{15}$ Using this classification, $81.25 \%$ of our patients had ferritin levels that were inadequate for hair cycle. In contrast, only $25 \%$ of the patients in their study had inadequate ferritin levels.

A similar study was done by Olsen, et al. at Duke University Hair Disorders Clinic in North Carolina in 2009. ${ }^{16}$ They had categorized serum ferritin levels into three groups: serum ferritin $\leq 15 \mathrm{ng} / \mathrm{mL}$, serum ferritin $\leq 40 \mathrm{ng} / \mathrm{mL}$ and serum ferritin $\leq 70 \mathrm{ng} / \mathrm{mL}$. Their findings were similar to ours as $7.7 \%$ of patients with female pattern hair loss had serum ferritin $\leq 15 \mathrm{ng} /$ $\mathrm{mL}, 45.6 \%$ had serum ferritin $\leq 40 \mathrm{ng} / \mathrm{mL}$ and $75.4 \%$ had serum ferritin $\leq 70 \mathrm{ng} / \mathrm{mL}$. The trend was similar in patients with chronic telogen effluvium with $11.5 \%$ having serum ferritin $\leq 15 \mathrm{ng} / \mathrm{mL}, 53.1 \%$ having serum ferritin $\leq 40 \mathrm{ng} / \mathrm{mL}$ and $75 \%$ having serum ferritin $\leq 70 \mathrm{ng} / \mathrm{mL}$. The comparison with iron deficiency anaemia was striking as only $2.1 \%$ of patients with female pattern hair loss and $5.2 \%$ with chronic telogen effluvium had iron deficiency anaemia. Moeinvaziri et al. in their study done in Iran also discovered that while mean haemoglobin levels were comparable in women with telogen effluvium and control subjects (12.6 g/dL vs. $12.9 \mathrm{~g} / \mathrm{dL}, \mathrm{p}=0.102)$, the difference in mean ferritin levels were stark $(16.3 \pm 12.6 \mathrm{ng} / \mathrm{mL}$ vs. $60.3 \pm 50.1 \mathrm{ng} / \mathrm{mL}, \mathrm{p}<0.001) .{ }^{17}$. This leads us to two important points. The first is that blood haemoglobin levels are not true indicators of hair iron content. The second more pertinent observation is that the body iron reserve is preferentially distributed in blood as compared to hair, which is considered less essential for general well being of an individual.

In our study, 63 (78.8\%) patients were euthyroid, 12 (15\%) hypothyroid and 5 (6.25\%) hyperthyroid. Among the patients with thyroid abnormalities, 4 (33.3\%) had subclinical hypothyroidism and 4 (80\%) had subclinical hyperthyroidism. The results in our study concord with that of Malkud's, ${ }^{5}$ where all the female patients with diffuse hair loss were euthyroid. Similarly, in the study done by Zhang et al. ${ }^{15}$, only two patients $(11.76 \%)$ had slight deviations of TSH level while T3 and T4 levels were within the normal limits in all the patients.

In our study, $27.78 \%$ of the participants with alopecia areata had thyroid dysfunction out of which all except one had hypothyroidism. Similar results were obtained by studies conducted in Nepal where thyroid function abnormalities were detected in $17.3 \%$ of participants with alopecia areata out of which only one had hyperthyroidism. ${ }^{18}$

Haemoglobin, iron and thyroid blood parameters may change during the course of illness. Our study being a cross sectional one, could not capture data at specific times during the course of the condition. Similarly, the sample in our hospital based study may not be representative of the general population. Many people with acquired alopecias may choose not to visit a clinic for their condition. Another limitation of our study was a disproportionate sample where patients with alopecia areata and female pattern hair loss constituted less than $40 \%$ of the study population.

Our study also did not include a control population. The cost of investigating haemoglobin, thyroid profile and iron profile in our hospital is around 25 US dollars, while the average per capita income per month in Nepal is around 70 US dollars. Health care in Nepal is usually paid by individuals and we could not justify asking patients with non-hair related complaints to spend almost two weeks' wages on these investigations. We also did not investigate antibodies against thyroid peroxidase and thyroglobulin as the cost would have been increased further by 65 US dollars.

\section{Conclusion}

This study has investigated haemoglobin, iron profile and thyroid function in females with telogen effluvium, alopecia areata or female pattern hair loss who visited our outpatient clinic in one year. Although haemoglobin levels were within normal limits, inadequate ferritin levels for normal hair cycle were observed in more 
than $75 \%$ of the participants belonging to each group. This study shows that haemoglobin levels are not reflective of true iron status. We therefore recommend investigating iron profile in all female patients with telogen effluvium, alopecia areata or female pattern hair loss. As the majority of our patients were euthyroid, the value of investigating thyroid function in acquired alopecias is debatable, especially in a resource limited setting.

\section{References}

1. Schmitt JV, Ribeiro CF, Souza FH, Siqueira EB, Bebber FR. Hair loss perception and symptoms of depression in female outpatients attending a general dermatology clinic. An Bras Dermatol 2012;87:412-7. https://doi.org/10.1590/s036505962012000300010

2. Franca K, Rodrigues TS, Ledon J, Savas J, Chacon A. Comprehensive overview and treatment update on hair loss. J Cosmet Dermatol Sci Appl 2013;3:18. https://doi.org/10.4236/jcdsa.2013.33A1001 .

3. Poonia K, Thami G, Bhalla M, Jaiswal S, Sandhu J. NonScarring Diffuse Hair Loss in Women: a Clinico-Etiological Study from tertiary care center in North-West India. J Cosmet Dermatol 2019;18(1):401-7. https://doi.org/10.1111/ jocd.12559

4. Hordinsky MK. Overview of alopecia areata. J Investig Dermatol Symp Proc 2013;16(1):S13-5. https://doi.org/10.1038/jidsymp.2013.4.

5. Malkud S. A hospital-based study to determine causes of diffuse hair loss in women. J Clin Diagn Res 2015 Aug;9(8):WC01-4. https://doi. org/10.7860/JCDR/2015/14089.6170

6. Malkud S. Telogen effluvium: A review. J Clin Diagn Res 2015;9(9):WE01-3. https://doi.org/10.7860/ JCDR/2015/15219.6492

7. Grover C, Khurana A. Telogen effluvium. Indian J Dermatol Venereol Leprol 2013;79(5):591-603. https://doi.org/10.4103/0378-6323.116731

8. Rook A. Endocrine influences on hair growth. $\mathrm{Br}$ Med J 1965 Mar;1(5435):609-614. https://doi. org/10.1136/bmj.1.5435.609

9. Sinclair R. Diffuse hair loss. Int J Dermatol 1999 May; 38: 8-18. https://doi.org/10.1046/j.13654362.1999.00003.x.

\section{Acknowledgements}

The authors would like to thank all the participants in this study and all the faculties, residents and staff of the department of Dermatology and Venereology, NMCTH for their cooperation in conducting this study.

10. Inui S. Trichoscopy for common hair loss diseases: algorithmic method for diagnosis. J Dermatol 2011;38(1):71-5. https://doi.org/10.1111/j.13468138.2010.01119.x

11. Koulouri O, Gurnell M. How to interpret thyroid function tests. Clin Med 2013 Jun;13(3):282-6. https://doi.org/10.7861/clinmedicine.13-3-282

12. Sinclair R. There is no clear association between low serum ferritin and chronic diffuse telogen hair loss. Br J Dermatol 2002 Nov;147(5):982-4. https:// doi.org/10.1046/j.1365-2133.2002.04997.x

13. Deo K, Sharma YK, Wadhokar M, Tyagi N. Clinicoepidemiological observational study of acquired alopecias in females correlating with anemia and thyroid function. Dermatol Res Pract 2016; 2016:1-5. https://doi. org/10.1155/2016/6279108

14. Sinha A, Manandhar N. Prevalence of Anemia among Women: A Hospital-Based Study in Eastern Nepal. Janaki Med Coll J Med Sci 2020;8:43-7. https://doi.org/10.3126/jmcjms.v8i2.33977

15. Zhang $X$, Caulloo S, Zhao Y, Zhang B, Cai Z, Yang J. Female pattern hair loss: clinico-laboratory findings and trichoscopy depending on disease severity. Int J Trichology 2012; 4:23-8. https://doi. org/10.4103/0974-7753.96082

16. Olsen EA, Reed KB, Cacchio PB, Caudill L. Iron deficiency in female pattern hair loss, chronic telogen effluvium, and control groups. J Am Acad Dermatol 2010;63:991-9. https://doi. org/10.1016/j.jaad.2009.12.006

17. Moeinvaziri M, Mansoori P, Holakooee K, Safaee Naraghi Z, Abbasi A. Iron status in diffuse telogen hair loss among women. Acta Dermatovenerol Croat 2009;17:279-84.

18. Marahatta S, Agrawal S, Mehata K. Alopecia Areata and Thyroid Dysfunction Association - A Study from Eastern Nepal. Kathmandu Univ Med J 2018;16:161-5. 